\title{
Determinants of territory size of the dusky gregory
}

\author{
R.-Q. JAN*†, C.-T. Ho† And F.-K. ShIAH† \\ *Institute of Zoology, Academia Sinica, Taipei, Taiwan 11529, Republic of China \\ and $\ddagger$ Institute of Oceanography, National Taiwan University, Taipei, Taiwan, Republic \\ of China
}

(Received 30 October 2002, Accepted 1 October 2003)

\begin{abstract}
To test the effect of food abundance and intruder pressure as determinants of territory size, the dusky gregory Stegastes nigricans were used as subjects on a coral reef in southern Taiwan during November to December 2000. Adults were used as intruders to provoke aggressiveness in a conspecific territory owner. The owner's maximum distance of attack (MDA) was used to delineate the territory size. While the owner of a territory appeared to defend a single boundary against different conspecifics, size variations among territories were evident. The effect of an intruder's identity on territory-size regulation was not clear because for each territory examined, the MDA was found to be neither linked to the body size of the intruder nor to the amount of algae in the intruder's territory. Moreover, no significant differences were found between the MDAs that the owner maintained against neighbours and non-neighbours even though, when conspecifics intruded in pairs, the probability was significantly higher for the first attack to be launched on a neighbour than on a non-neighbour. Also when a neighbour and a non-neighbour appeared simultaneously near the territory, the bite rate against the neighbour was also significantly higher. An inverse relationship between the amount of algae in the defended territory and the MDA of the owner indicates that food abundance might account for variations among territories. By contrast, territory size was not linked to the body size of the owner.

(C) 2003 The Fisheries Society of the British Isles
\end{abstract}

Key words: damselfish; familiarity; food abundance; maximum distance of attack; neighbour; Stegastes nigricans.

\section{INTRODUCTION}

On coral reefs, many fishes of the genus Stegastes (Pomacentridae) hold permanent territories of various sizes (Allen \& Emery, 1985; Harrington, 1993; Letourneur, 2000). These fishes generally defend a series of concentric territorial boundaries against heterospecific intruders with different feeding habits (Thresher, 1976).

In general, the territory of a Stegastes fish is established for the defence and acquisition of resources such as food, shelter, or mates (Thresher, 1976; Itzkowitz \& Slocum, 1995; Karino, 1995; Letourneur et al., 1997). Along with the benefits of priority of access to the resources, the defence of a territory also has costs. According to optimal territory-size models (Hixon, 1980, 1981;

$†$ Author to whom correspondence should be addressed. Tel.: +886227899519; fax: +886227858059 ; email: rqjan@ccvax.sinica.edu.tw 
Davies \& Houston, 1984), the costs and benefits of territory defence are apt to change following an incremental change in territory size. Using food abundance and intruder pressure as determinants, the model predicts that optimal territory size for concentric territories increases as the benefits of excluding an intruder increase (Thresher, 1976; Grant, 1997). This prediction is supported by findings in Stegastes, that for fishes in many interspecific confrontations, the territory size and the intensity of the owner's attacks are positively related to the degree of mutual ecological overlap (Thresher, 1976; Kohda, 1981; Harrington \& Losey, 1990; Draud \& Itzkowitz, 1995).

By contrast, factors leading to size variations among different territories are less clear. A simple model predicts that the optimal territory size of a fish should generally decrease with either an increase in food abundance or intruder pressure (Grant, 1997). Apart from the amounts of algae that may vary among territories and the different body sizes of intruders who have different levels of familiarity with the territory owner (Harrington, 1993; Letourneur, 2000), the effect of body-size differences of territory owners also needs scrutiny because fishes with a large body size might have greater energy demands than smaller individuals and, hence require a larger defended area to meet those demands.

In this study, a population of the territorial dusky gregory Stegastes nigricans (Lacepède), was used as subjects to test whether food abundance and intruder pressure can account for variations in the size of different territories. This fish feeds mainly on filamentous algae and attached detritus (Lobel, 1980; Wilson \& Bellwood, 1997), and both sexes defend individual territories against all intruders and food competitors (Karino \& Kuwamura, 1997). Experiments were designed to examine and compare effects of body size, resource abundance (amount of algae), and mutual familiarity (neighbour or non-neighbour) on the territory size of this fish species. The aim was to shed some light, not only on determinants of territory size, but also on the relationship between territory owners and their neighbouring conspecifics.

\section{MATERIALS AND METHODS}

Field work was carried out in a protected area near the water inlet of the Third Nuclear Power Plant in southern Taiwan $\left(21^{\circ} 57^{\prime} \mathrm{N} ; 120^{\circ} 45^{\prime} \mathrm{E}\right)$. The study site was dominated by colonies of branching Acropora corals. Stegastes nigricans conspicuously defended welldefined territories comprising small patches of filamentous algae growing on dead acroporoid coral branches (Fig. 1). As in other areas, the fish live at a high density with neighbours nearby (Karino \& Kuwamura, 1997; Letourneur, 2000).

Adult $S$. nigricans individuals were collected by selective angling from the study area by SCUBA. Live specimens, whose fork length $\left(L_{\mathrm{F}}\right)$ were in the range of $10 \cdot 3-12 \cdot 8 \mathrm{~cm}$, were kept separately in captivity in perforated, transparent plastic cylindrical bottles (height $12 \mathrm{~cm}$, radius $7 \mathrm{~cm}$, wall thickness $<0.01 \mathrm{~mm}$ ). These individuals were then used as intruders to provoke aggressive behaviour by conspecific territory owners (Myberg \& Thresher, 1974). After the experiment, they were released at the site where they had been caught. All field experiments were conducted by means of SCUBA between 29 November and 23 December 2000, a period when no spawning was observed in this population.

The main setup was composed of a fine suspended cableway which was fixed to an upright steel rod $1 \mathrm{~m}$ in height on each side of the experimental territory. This cableway functioned as a rail to facilitate control of bottle movement. Before each experiment, blank-tests were done using empty bottles. In all cases the focal territorial fish neither approached nor evaded the bottle. Three factors assumed to be related to territory size 


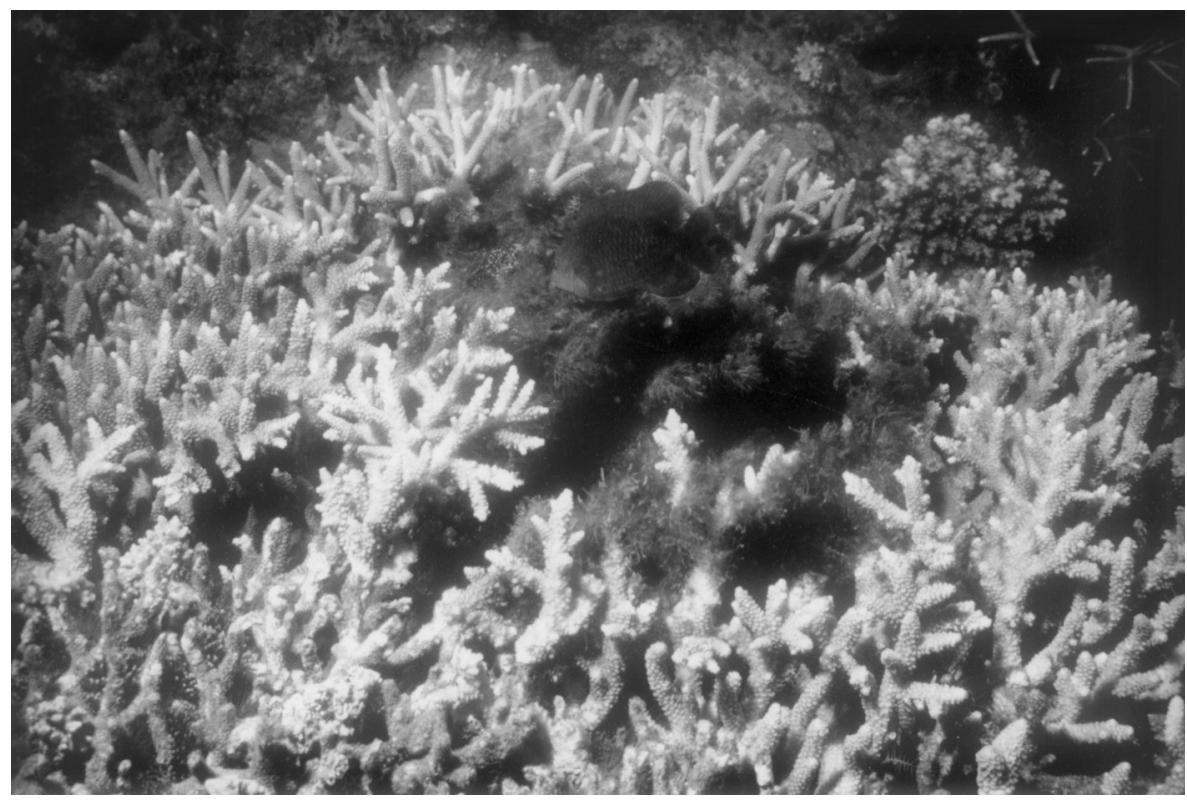

FIG. 1. An adult Stegastes nigricans over a patch of algal mat growing on dead coral branches. The algal mat forms the core area of the territory. The maximum distance of attack (MDA) was measured between the outer boundary of the algal mat and the point where attacks on an intruder occurred.

were examined: the body size of the fish [as an indicator of food requirement and fighting ability (Neat et al., 1998)], the amount of algae in the territory (as an indicator of resource abundance), and the familiarity between the fish engaged in the confrontation. The amount of algae in a territory was quantified by the total length of coral branches covered by growing algae (Karino, 1995; Letourneur, 2000). The length measurement of coral branches was made using a measuring tape. For each territory holder, the experimental intruder was identified as a neighbour or non-neighbour: a fish collected from the same colonial group was a neighbour, otherwise it was a non-neighbour. Pearson's correlations $(r)$ were used to analyse the relationships between different factors, and paired $t$-tests were used to test differences in the same factor under different conditions.

Three variables were assigned to quantify territory-size characteristics. The maximum distance of attack by the territory owner [MDA, Harrington (1993); c.f. MDD, i.e. maximum distance of defence, in Myrberg \& Thresher (1974)] was used to delineate the territory size. In addition, both priority of defence by the owner and bite rates on intruders at a fixed distance were examined to distinguish pressures from different intruders. These variables are defined below. Due to limitations of the number of territories available for simultaneous experiments, changes in sample sizes occurred between experiments.

\section{MAXIMUM DISTANCE OF ATTACK}

A bottled intruder was moved along the suspended cableway by a fine trailing line toward the territory at a speed of $0.5 \mathrm{~m} \mathrm{~min}^{-1}$. The movement was started $300 \mathrm{~cm}$ away from the outer boundary of the algal mat. Eventually a point was reached at which the territory owner began to attack (bite) the intruder. The distance between this point and the outermost boundary of the algal mat was measured as the MDA. A total of 24 territories was used. Each was treated, one at a time, using four different intruders (including two neighbours and two non-neighbours). ANCOVA was used to test for 
the difference in MDA between neighbour and non-neighbour intrusions. One-way ANOVA was used to test for the difference in MDA among territories.

\section{PRIORITY OF DEFENCE}

A pair of intruders, a neighbour and a non-neighbour, was moved simultaneously along two parallel cableways toward a territory, to test whether the owner would discriminate between the intruders by targeting one or the other first. A total of 15 territories was studied. For each territory, the experiment was repeated, but the positions of the fish-holding bottles were changed; also the direction of bottle movement was varied. For the four observations for each focal territorial fish, only unanimous results were used (i.e. a split decision counts as a tie) in a binomial test.

\section{BITE RATES AGAINST INTRUDERS}

On the cableway, the intruder was placed $60 \mathrm{~cm}$ (and in repetitive experiments, $30 \mathrm{~cm}$ ) away from the outermost boundary of the algal mat in the experimental territory and 2 min counts of the owner's number of bites were made and used as an indicator of the territory owner's vigour of attack. In the experiment, each territory was invaded by two neighbours and two non-neighbours. These intruders were arranged into two combinations: solitary or in pairs of neighbour and non-neighbour. Both the solitary test and the paired test were made to examine if mutual familiarity would affect a territory owner's bite rate. The solitary test also facilitated the examination of the relationship between the bite rate of a territory owner and the amount of algae in its territory.

In the solitary test, a total of 12 territories was used, each with intrusions of 30 and $60 \mathrm{~cm}$ distances to provoke a response. ANCOVA was used to test for the differences in the bite rate between intrusions from these two distances. In the paired test, 10 territories were used. There were four pair combinations. In each pair combination, the observation was replicated with the intruders' positions exchanged.

\section{RESULTS}

\section{MAXIMUM DISTANCE OF ATTACK}

\section{Intruder effect}

MDAs collected from the 24 territories in the experiment ranged from 55 to $280 \mathrm{~cm}$ (total $n=96$ ). MDAs did not differ significantly between neighbour $v$. non-neighbour intrusions (ANCOVA, d.f. $=1$ and $91, P=0 \cdot 86$ ). In addition, there was no significant effect of the covariate body size of the intruder (d.f.= 1 and $91, P=0.72$ ), no significant effect of the covariate amount of algae in the intruder's territory (d.f. $=1$ and $91, P=0.52$ ) and no significant interaction between intruder's body size and the amount of algae in its territory (d.f.= 1 and $91, P=0 \cdot 58)$.

\section{Differences among territories}

MDAs differed significantly among owners (ANOVA, d.f.=1 and 23, $P<0.001)$. Further analysis showed that MDA was not related to the owner's $L_{\mathrm{F}}(r=0 \cdot 005, n=24, P=0 \cdot 98)$. A negative correlation, however, was found between the MDA and the amount of algae in the owner's territory ( $r=-0.42, n=24, P=0 \cdot 04$; Fig. 2), indicating a trend by which the greater the amount of algae the owner possessed in its territory, the smaller was the territory size. 


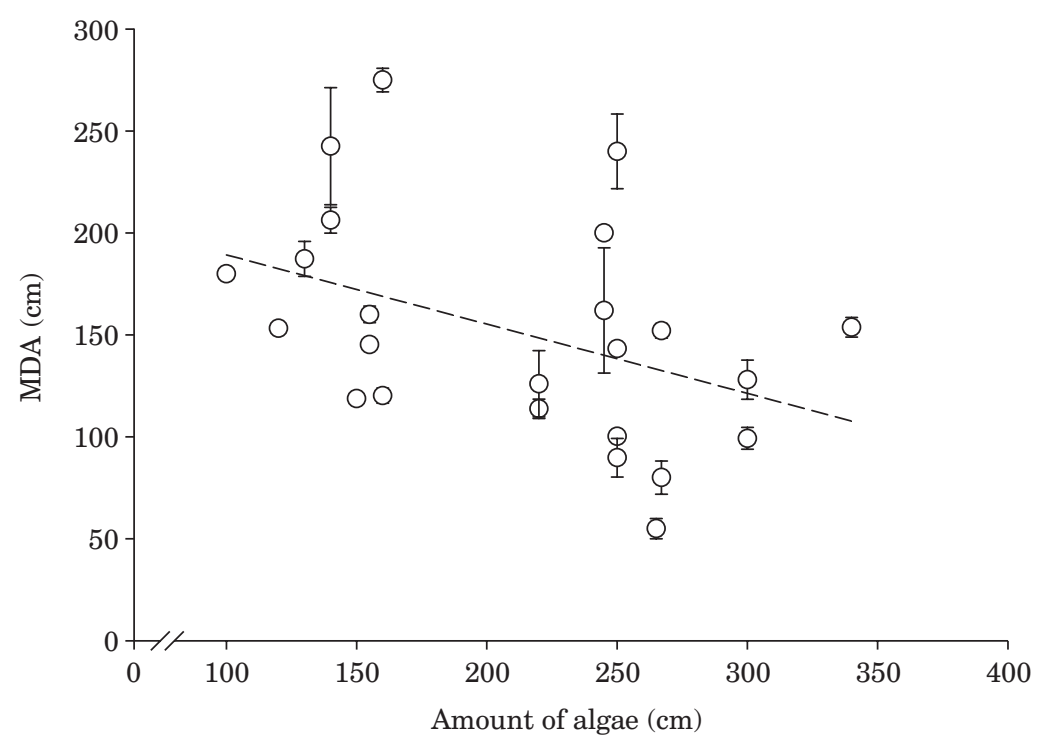

FIG. 2. Relationship between the mean \pm S.D. territory owner's maximum distance of attack and the amount of algae in the territory. The dashed line was fitted by: $y=-0 \cdot 34 x+223 \cdot 2$.

\section{PRIORITY OF DEFENCE}

In the 15 territories examined, 10 owners attacked the neighbours first, two owners attacked the non-neighbours first, and three owners showed split decisions (binomial test, $P=0 \cdot 02$ ).

\section{BITE RATES}

\section{Against solitary intruders}

The territory owner approached and bit almost all the solitary intruders occurring at $60 \mathrm{~cm}$ from the outermost boundary of the algal mat (bite rate range: $0-30$ times per $2 \mathrm{~min}$ ). When the intruders were moved forward and stopped $30 \mathrm{~cm}$ away, the owner proceeded with attacks (bite rate range: 1-48 times per $2 \mathrm{~min}$ ). Results of the ANCOVA showed that the bite rate was negatively related to the covariate amount of algae in the defended territory (d.f. $=1$ and $90, P<0.001 ;$ Fig. 3 ) and affected by the distance at which the intrusion occurred (d.f. $=1$ and 90, $P=0.02$ ). Territory owners were more aggressive toward a solitary intruder $30 \mathrm{~cm}$ away than toward one $60 \mathrm{~cm}$ away. With the same amount of algae in the territory, the difference between bite rates was $9 \cdot 3$ times per 2 min. By contrast, there was no significant effect of mutual familiarity (ANCOVA, d.f. $=1$ and $91, P=0 \cdot 87$ ), no significant interaction between algae and distance (d.f. $=1$ and $91, P=0 \cdot 20)$ and no significant interaction between algae and mutual familiarity $($ d.f. $=1$ and $91, P=0 \cdot 88)$.

\section{Neighbour v. non-neighbour intrusions}

When a territory owner simultaneously faced two intruders $30 \mathrm{~cm}$ away, one being a neighbour and the other a non-neighbour, the bite rate for the intruding 


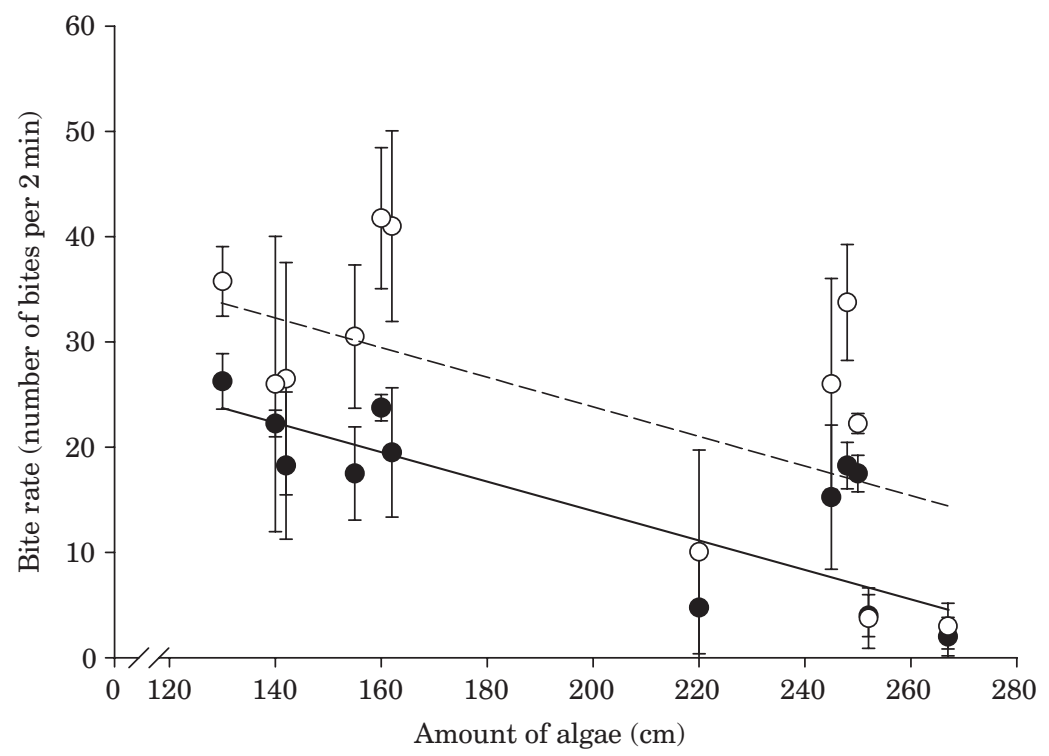

FIG. 3. Relationship between the amount of algae in a fish's territory and its bite rate (mean \pm S.D., total $n=96)$ against an intruder $60(\bullet,-)$ and $30 \mathrm{~cm}(\bigcirc,---)$ away from the algal mat. The lines were fitted by: $60 \mathrm{~cm}, y=-0 \cdot 13 x+42 \cdot 2 ; 30 \mathrm{~cm}, y=-0 \cdot 13 x+51 \cdot 5$.

neighbour ranged $0-40$ times per 2 min (mean $=13 \cdot 1$ times per $2 \mathrm{~min}$ ), and for the non-neighbour, it ranged $0-29$ times per 2 min (mean $=8 \cdot 5$ times per $2 \mathrm{~min}$ ). The difference between bite rates against neighbours and non-neighbours was significant (paired $t$, d.f. $=79, P<0 \cdot 01$ ). To reduce the risks of type II errors, the difference in bite rates was further analysed in terms of $L_{\mathrm{F}}$ and amount of algae in the intruder's territory. The results showed that bite rates did not differ between larger intruders and smaller intruders (paired $t$, d.f. $=79, P=0.95$ ) or between intruders with more algae in their territory and those with less algae (paired $t$, d.f. $=79, P=0.99$ ).

\section{DISCUSSION}

According to the optimal territory-size model, both food abundance and intruder pressure play important roles in regulating the size of the territory of a fish. In this study, an inverse relationship was found between the amount of algae in the defended territory and the MDA of the territorial S. nigricans (Fig. 2 ), indicating that food abundance might account for size variations among different territories. The fish were not defending a classical feeding territory where a bigger territory included more food (Grant, 1997), but were guarding a valuable patch of filamentous algae in the territory (Fig. 1). Guarding a larger zone of exclusion around the patch should increase with the value of the resource and the perceived threat to the resource. It is unusual that fish with more valuable patches have smaller MDAs and are less aggressive toward intruders (Figs 2 and 3). Perhaps fish with less food in their patches are hungrier and value their patch more than a fish with more food. By contrast, the effect of 
an intruder's identity on territory size regulation was not evident since neither the MDA nor the bite rate of the owner was linked to the body size of the intruder or to the amount of algae in the intruder's territory. Also, no significant differences were found between the MDAs the owner maintained against neighbours and non-neighbours. In models of optimal territory size, intruder pressure is indicated as the rate of defence, not simply whether an intruder is a neighbour or not. In this study, the rates of intrusions were not measured due to difficulties of density manipulation. Hence it remains uncertain whether the territory size is influenced by the territorial pressure exerted by neighbours as in contiguous territories (Grant, 1997).

Body size is a presumptive indicator of food requirement and fighting ability, and an influence of body size on intraspecific competition is often expected in coral reef fishes (Karino, 1995; Robertson, 1996; Neat et al., 1998). For example, larger individuals defended larger areas or won intraspecific contests in territorial Stegastes spp. in some studies, particularly those involving both juveniles and adults and hence including a wide range of body sizes $[e . g .1-6 \mathrm{~cm}$ total length, $L_{\mathrm{T}}$, in $S$. partius (Poey) and $S$. planifrons (Cuvier) (Harrington, 1993 ) and $2-12 \mathrm{~cm}$ in $S$. nigricans (Letourneur, 2000)]. For the narrow range of fish in this study $\left(10 \cdot 3-12 \cdot 8 \mathrm{~cm} L_{\mathrm{F}}\right)$, the body size of either the territory owner or the intruder did not seem to account for differences in MDA. If there were body-size effects in territory defence, they might have been overridden by other factors. Meanwhile, the lack of links between MDA and the amount of algae in the intruder's territory indicates that a territory owner might have evaluated the threat of the intrusion based on factors other than the intruder's resource-holding power (Parker, 1974). By combining the findings on body-size asymmetry and differences in amounts of algae, it is very likely that this threat to a territory holder might have primarily arisen from the degree of mutual resource overlap. In other words, a territory owner would defend a single boundary against conspecifics, since they possess the same feeding demand and feeding habit.

For a territorial S. nigricans, although its familiarity with intruders did not affect the regulation of its territory size, familiarity did affect its defence of resources in its territory. For example, when a neighbour and a non-neighbour simultaneously approached a third party's territory, the owner would more likely choose to attack the neighbour first. Also, while facing the two intruders $30 \mathrm{~cm}$ away, the owner would bite the neighbour more frequently. Thus, the so-called dear-enemy phenomenon that the territory owner responds more aggressively to intrusions by non-neighbours than neighbours (Miller, 1978; Temeles, 1994) did not seem to occur in S. nigricans. It is possible that a neighbour might pose greater threats to a territory owner than a non-neighbour. In a removal experiment of $S$. nigricans, it was found that after the removal of a territory owner, the nearest neighbour might instantly come to occupy this vacant territory (unpubl. data). Jan (1991, 1997) studied egg-caring of damselfishes including Abudefduf vaigiensis (Quoy \& Gaimard) and Chromis fumea (Tanaka) which hold temporary spawning territories and found that after removal of some members of leks, the neighbouring conspecifics were, in all cases, the first to prey on the eggs in nests whose owners were removed. The question remaining, is why a territorial $S$. nigricans should, on the one hand, discriminate 
against its neighbour-intruders in the case of choice of defence and, on the other hand, maintain a single-boundary territory against conspecifics of different identities. Further information is needed to answer this question.

We thank A.Y. Cheng and Y.H. Liu for help with the fieldwork, and three anonymous reviewers for commenting on the manuscript. This research was funded by the National Science Council of Taiwan, R.O.C. under research grants NSC 89-2611-B-001-003, 89-2311-B-001-162, 90-2311-B-001-161 and 90-2621-B-001-002. The experiments comply with the current laws of the country in which they were performed.

\section{References}

Allen, G. R. \& Emery, A. R. (1985). A review of the pomacentrid fishes of the genus Stegastes from the Indo-Pacific with the description of two new species. Indo-Pacific Fishes 3, 1-32.

Davies, N. B. \& Houston, A. I. (1984). Territory economics. In Behavioural Ecology: an Evolutionary Approach (Krebs, J. R. \& Davies, N. B., eds), pp. 148-169. London: Blackwell Science.

Draud, M. J. \& Itzkowitz, M. (1995). Interspecific aggression between juveniles of two Caribbean damselfish species (genus Stegastes). Copeia 1995, 431-435.

Grant, J. W. A. (1997). Territoriality. In Behavioural Ecology of Teleost Fishes (Godin, J.-G. J., ed.), pp. 81-103. Oxford: Oxford University Press.

Harrington, M. E. (1993). Aggression in damselfish: adult-juvenile interactions. Copeia 1993, 67-74.

Harrington, M. E. \& Losey, G. S. (1990). The importance of species identification and location on interspecific territorial defense by the damselfish, Stegastes faciolatus. Environmental Biology of Fishes 27, 139-145.

Hixon, M. A. (1980). Food production and competitor density as the determinants of feeding territory size. American Naturalist 115, 510-530.

Hixon, M. A. (1981). An experimental analysis of territoriality in the California reef fish Embiotoca jacksoni (Embiotocidae). Copeia 1981, 653-655.

Itzkowitz, M. \& Slocum, C. J. (1995). Is the amount of algae related to success in the beaugregory damselfish? Marine Behaviour and Physiology 24, 243-250.

Jan, R. Q. (1991). Malicious neighbours in leks of sergeant major damselfish, Abudefduf vaigiensis. Bulletin of the Institute of Zoology, Academia Sinica 30, 49-53.

Jan, R. Q. (1997). Sympatric spawning of the damselfishes Chromis fumea and Pomacentrus coelestis on the northern coast of Taiwan. Zoological Studies 36, 26-32.

Karino, K. (1995). Male-male competition and female mate choice through courtship display in the territorial damselfish Stegastes nigricans. Ethology 100, 126-138.

Karino, K. \& Kuwamura, T. (1997). Plasticity in spawning visits of female damselfish, Stegastes nigricans: effect of distance to mates. Behavioral Ecology and Sociobiology 41, 55-59.

Kohda, M. (1981). Interspecific territoriality and agonistic behavior of temperate pomacentrid fish, Eupomacentrus altus (Pisces: Pomacentridae). Zeitschritf für Tierpsychologie 56, 205-216.

Letourneur, Y. (2000). Spatial and temporal variability in territoriality of a tropical benthic damselfish on a coral reef (Reunion Island). Environmental Biology of Fishes 57, 377-391.

Letourneur, Y., Galzin, R. \& Harmelin-Vivian, M. (1997). Temporal variations in the diet of the damselfish Stegastes nigricans (Lacepède) on a Reunion fringing reef. Journal of Experimental Marine Biology and Ecology 217, 1-18.

Lobel, P. S. (1980). Herbivory by damselfishes and their role in coral reef community ecology. Bulletin of Marine Science 30, 273-289.

Miller, R. J. (1978). Agonistic behavior in fishes and terrestrial vertebrates. In Contrasts in Behavior: Adaptation in the Aquatic and Terrestrial Environments (Reese, E. S. \& Lighter, F. J., eds), pp. 292-294. New York: Wiley-Interscience Publication. 
Myrberg, A. A. \& Thresher, R. E. (1974). Interspecific aggression and its relevance to the concept of territoriality in reef fishes. American Zoologist 14, 81-96.

Neat, F. C., Huntingford, F. A. \& Beveridge, M. M. C. (1998). Fighting and assessment in male cichlid fish: the effects of asymmetries in gonadal state and body size. Animal Behaviour 55, 883-891.

Parker, G. A. (1974). Assessment strategy and the evolution of fighting behavior. Journal of Theoretical Biology 47, 223-243.

Robertson, D. R. (1996). Interspecific competition controls abundance and habitat use of territorial Caribbean damselfishes. Ecology 77, 885-899.

Temeles, E. J. (1994). The role of neighbours in territorial system: when are they 'dear enemies'? Animal Behaviour 47, 339-350.

Thresher, R. E. (1976). Field analysis of the territoriality of the threespot damselfish, Eupomacentrus planifrons (Pomacentridae). Copeia 1976, 266-276.

Wilson, S. \& Bellwood, D. R. (1997). Cryptic dietary components of territorial damselfishes (Pomacentridae, Labroidei). Marine Ecology Progress Series 153, 299-310. 